\title{
CD44-Positive Cells and Hyaluronan are a Hallmark of a Rat Model of Aristolochic Acid Nephropathy
}

\author{
Anne-Emilie Decleves ${ }^{1,2 *}$, Agnieszka Pozdzik², T Baudoux², Isabelle Habsch¹, Eric De Prez², Bruno Flamion ${ }^{1}$, Joelle Nortier $^{2}$ and Nathalie \\ Caron ${ }^{1}$ \\ ${ }^{1}$ Molecular Physiology Research Unit, University of Namur, Belgium \\ ${ }^{2}$ Laboratory of Experimental Nephrology, Faculty of Medicine, Université Libre de Bruxelles, (ULB), Belgium
}

\begin{abstract}
Background: Aristolochic acid (AA) Nephropathy (AAN) is characterized by tubulointerstitial injury leading to fibrosis and tubular atrophy. Defective regeneration of tubular cells was hypothesized as a mechanism leading to Proximal Tubular Epithelial Cell (PTEC) atrophy. Here, we examined the distribution of CD44, an adhesion molecule involved in differentiation, and its main ligand, Hyaluronan (HA), in an experimental AAN model.
\end{abstract}

Methods: Wistar rats were injected daily with AA or vehicle during 35 days. Tubular enzymuria and tissue expression of CD44 and HA were evaluated at days 3, 7, 10, 21 and 35. Co-expressions of CD44 and PCNA (proliferation), vimentin (mesenchymal phenotype), $\alpha$-SMA (myofibroblasts), and CD133 (progenitor cells) were investigated.

Results: AA induced acute tubular damage followed by PTEC atrophy. In controls, CD44 was limited to the basolateral membrane of collecting ducts while HA expression was confined to the medullary interstitium. CD44 was overexpressed as soon as 3 days after AA exposure, spreading to the apical and basolateral membranes of dedifferentiated PTECs and appearing on numerous interstitial cells along with marked HA accumulation around necrotic tubules. Both CD44 and HA expressions increased steadily throughout the 1-month follow-up. A large amount of tubular and interstitial CD44+ cells were proliferative (PCNA+) and mesenchymal-like (vimentin+). Few CD44+ cells expressed $\alpha$-SMA or CD133.

Conclusions: Our results suggest CD44 is a strong marker of dedifferentiation, and thus of regeneration, in a rat model of AAN. Concomitant HA accumulation around necrotic tubules may create a sustained crosstalk between CD44+ cells and their interstitial ligand. PTEC atrophy is accompanied by overexpression, not deficiency, of the CD44-HA axis.

Keywords: CD44; Hyaluronan; Tubular Dedifferentiation; Progressive chronic kidney disease; Aristolochic acid nephropathy

\section{Introduction}

Initially called Chinese herb nephropathy, Aristolochic Acid Nephropathy (AAN) was reported in 1992 in young Belgian women after intake of slimming pills containing root extracts of Aristolochia sp. [1,2]. AAN is a progressive chronic Tubulointerstitial (TI) disease characterized by tubular atrophy and dense TI fibrosis with relatively well-preserved glomeruli $[1,3]$. It is also found in various regions of the world where exposure to similar toxins is prevalent [4]. Clinically, AAN results in a rapid deterioration of renal function leading to end-stage renal disease [2]. Our group has developed an experimental model of AAN in rats [5]. This model recapitulates the structural and functional impairment of proximal tubular epithelial cells (PTECs) shown in humans [5,6]. Increased oxidative stress, prominent collagen deposits and TGF- $ß$ expression, impaired tubular regeneration [7], as well as massive inflammatory cells infiltration [3] are hallmarks of experimental AAN. The latter has a biphasic evolution with an acute early phase (3-10 days) of tubular necrosis followed by a chronic phase (after 14 days) of interstitial fibrosis and tubular atrophy $[3,5]$. Interestingly, histological data suggest a defect of tubular repair leading to the hypothesis that incomplete regeneration of tubular cells could enhance the development of severe tubular atrophy in AAN [5].

Numerous studies have described the renal accumulation of CD44, an adhesion molecule involved in cell differentiation, and its main ligand, Hyaluronan (HA), a matrix glycosaminoglycan, in various renal diseases such as ischemia-reperfusion, lithiasis, or renal allograft rejection [8-13]. CD44 is a glycoprotein involved in cell-cell and cellmatrix interactions, in particular cell migration and tissue repair. CD44 is strongly upregulated in the kidney during proximal tubule regeneration [10,12]. Delayed resolution of inflammation and reduced HA clearance are observed in CD44-knockout mice recovering from renal, liver, or lung injuries [14-16]. Moreover, CD44 is a marker of undifferentiated mesenchymal cells [17]. HA, on the other hand, is a ubiquitous glycosaminoglycan found in the extracellular matrix of many tissues including the renal medulla, but not the cortex, except during inflammatory and ischemic injuries.

The current study was designed to examine the distribution and time course of CD44 and HA expression during experimental AAN.

*Corresponding author: Anne-Emilie Decleves, Laboratory of General Physiology, Molecular Physiology Research Unit (URPHYM) University of Namur 61, rue de Bruxelles,B-5000, Belgium, Tel: +32-81-724330; E-mail: anne-emilie.decleves@fundp.ac.be

Received June 12, 2013; Accepted August 30, 2013; Published September 02 2013

Citation: Decleves AE, Pozdzik A, Baudoux T, Habsch I, De Prez E, et al. (2013) CD44-Positive Cells and Hyaluronan are a Hallmark of a Rat Model of Aristolochic Acid Nephropathy. J Cytol Histol 4: 186. doi: 10.4172/2157-7099.1000186

Copyright: (C) 2013 Decleves AE, et al. This is an open-access article distributed under the terms of the Creative Commons Attribution License, which permits unrestricted use, distribution, and reproduction in any medium, provided the original author and source are credited. 


\section{Materials and Methods}

\section{Experimental protocols}

The experimental protocol approved by the local Ethic Committee for Animal Care was performed in 4-week-old male Wistar rats (Elevage Janvier, Le Genest Saint-Isle, France). Experimental procedures were conducted according to the National Guidelines for the Care and Use of Laboratory Animals. Weight-matched rats were randomly assigned to two groups. One group $(\mathrm{n}=30)$ received s.c. injections of AA (a mixture containing 40\% AAI and 60\% AAII, Acros Organics Co.) at $10 \mathrm{mg} / \mathrm{kg}$ bw daily for 35 days. AA was dissolved in polyethylene glycol (PEG) 400 (Fluka Chimie) to a final concentration of $10 \mathrm{mg} / \mathrm{ml}$ and diluted in distilled water before injection. The SHAM group $(n=30)$ was treated with a v/v solution of PEG 400 and distilled water only. Control rats $(\mathrm{n}=4)$ did not receive any treatment and were euthanized at day 0 . Body weights were measured weekly for adjustment of drug dosages. Six rats in each group were euthanized on days 3, 7, 10, 21 and 35, following a 24 -h period in a metabolic cage to collect urine. Blood sample was collected, and the kidneys were excised and immediately processed for further analysis.

\section{Biochemical evaluation of urinary tubular markers}

Urinary creatinine values were determined by a pseudokinetic Jaffe's method using a Creatinine Diagnostic Kit (Sigma-Aldrich) [5]. Total proteinuria was quantified by the Bradford binding assay as described in [18]. Urinary excretion of lysosomal enzyme N-Acetyl$ß$-D-Glucosaminidase (NAG) was measured by a colorimetric assay following the manufacturer's protocol (Roche Diagnostic). Urinary excretion of Leucine Aminopeptidase (LAP) was detected by a spectrofluorimetric assay as detailed previously [5].

\section{Histology}

Paraffin-embedded kidney sections were stained with PAS, hemalun, and Luxol fast blue to assess morphological alterations and with Sirius Red to detect collagen I and III deposits.

\section{Immunohistochemical procedures}

CD44 (mouse anti-rat antibody OX49, Pharmingen), vimentin (chicken anti-vimentin antibody, Chemicon), CD133 (rabbit antiCD133 antibody, Biorbyt), and $\alpha$-smooth muscle actin ( $\alpha$-SMA) (mouse anti- $\alpha$-SMA, DAKO) were detected on paraffin sections using a streptavidin-biotin immunoperoxidase method ( $A B C$ method) as detailed in previous publications $[3,7,8]$. Detection of HA was performed using a biotinylated HA-Binding Protein (HABP, Calbiochem). Kidney sections were first incubated for $1 \mathrm{~h}$ with HABP. The latter was revealed by Tyramin-Signal Amplification (TSA, Perkin Elmer). Peroxidase activity was visualized by incubating tissue sections in the presence of $\mathrm{H}_{2} \mathrm{O}_{2}$ and DAB in PBS. Counterstaining was performed with hemalun and Luxol fast blue.

\section{Immunofluorescent staining}

The co-expression of CD44 with PCNA (proliferation cell nuclear antigen), vimentin, CD133, or a-SMA was analyzed using a doublelabelling immunofluorescence method [19]. To avoid cross-reactivity between the secondary antibodies, antisera raised in different species were used. Sections were labelled sequentially at room temperature with the first primary monoclonal antibody followed by a biotinylated anti-mouse IgG and finally by Texas-Red-conjugated streptavidin. After these steps, sections were exposed to microwave irradiation to denature mouse immunoglobulins. Thereafter, sections were incubated for $1 \mathrm{~h}$ at room temperature with the second primary antibody, followed by FITC-conjugated secondary antibody for $30 \mathrm{~min}$. After final rinses in distilled water, sections were mounted in ProLong ${ }^{\oplus}$ Gold antifade reagent (Invitrogen).

\section{Morphometric analysis of marker immunoreactivity in renal tissue}

The relative area positively stained for HA and CD44 was assessed on a semi-quantitative basis by adapting a single-blind analysis of paraffin sections ( 1 section per animal). Slides were coded and analysed by two of us who was kept blinded of the treatment. To standardize the evaluation procedure, an additional lens engraved with a $1-\mathrm{cm}^{2}$ square grid was inserted in one of microscope eye pieces. Each paraffin section was scanned at $\times 400$ magnifications, and 15 square fields were evaluated. The degree of stained area was graded along an arbitrary scale.

The relative area occupied by vimentin, and $\alpha$-SMA was evaluated by a computer-assisted morphometric approach. Images were obtained with a DeltaPix digital camera (model DP200) and further analysed using the National Institute of Health Image J software (NIH, Bethesda, $\mathrm{MD}$ ) to quantify the percentage of stained area. Sections (one per animal) were analysed by scanning 10 fields at $\mathrm{x} 400$ magnification.

\section{Cell counts}

The frequency of CD44 or CD133-positive cells in the interstitial spaces was evaluated by a semi-quantitative analysis as described previously [8]. Briefly, the distribution of positive cells in the interstitium was performed on one section per animal. For each section, 10 square fields $\left(0.084 \mathrm{~mm}^{2} /\right.$ field $)$ were observed at $\mathrm{x} 400$ magnification. The incidence of CD133-positive collecting ducts was also evaluated at $\mathrm{x} 400$ magnification. As a whole, 100 collecting ducts were evaluated in each specific renal area (OSOM and ISOM). Of note, the presence of one single positive cell makes the tubule positive. Results were expressed as the percentage of CD133-positive collecting duct according to their distribution (OSOM, ISOM).

\section{mRNA quantification via real-time reverse transcriptase PCR}

Total RNA was extracted with the High Pure RNA Tissue Kit (Roche Diagnostics) according to the manufacturer's protocol. The mRNA quantification was performed using a 2-step real-time reversetranscriptase PCR (LightCycler, Roche Diagnostics). $\beta$-actin was used as the housekeeping gene and was purchased as ready to use (Life technologies). TGF- $\beta 1$ primers and probes were designed and purchased from Eurogentec. Relative gene expressions were calculated using the $2^{\text {-delta, delta CT }}$ method.

\section{Calculations and statistic}

Results are presented as mean values \pm SEM. The level for statistical significance was defined as $\mathrm{P}<0.05$. Mann-Whitney unpaired test was applied to compare AA, SHAM and control groups at each corresponding time point.

\section{Results}

\section{Time course of renal damage and TI lesions}

A significant decrease in body weight was observed from day 10 to day 35 in AA-treated rats compared to SHAM rats at corresponding time-points (day 10: $283 \pm 6$ vs $307 \pm 5$; day 21: $322 \pm 10$ vs $364 \pm 8$; day $35: 346 \pm 11$ vs $422 \pm 9$ g respectively, $\mathrm{P}<0.05)$. However, the kidney-to- 
body weight ratio significantly rose at days 21 and 35 in AA-treated rats, revealing renal hypertrophy (Figure 1A).

Proteinuria increased significantly as early as day 3 and persisted to day 35 in AA-treated rats (Figure 1B). In parallel, NAG enzymuria significantly increased from day 3 to day 35 (Figure $1 \mathrm{C}$ ), reflecting structural impairment of PTEC [5]. A transient increase in LAP, a membrane-bound brush border enzyme, was detected at days 7 and 10 , and then significantly decreased during the last days of observation (Figure 1D), confirming progressive PTEC atrophy. Conventional microscopy using PAS staining revealed morphological alterations as early as day 3: swelling of tubular cells, progressive loss of tubular brush border and a significant increase in infiltrating interstitial cells, mostly in the outer stripe of the outer medulla (OSOM) and in the medullary rays. As illustrated in (Figures $1 \mathrm{~F}-\mathrm{H}$ ), patchy zones of necrotic PTECs associated with significant cell infiltration were observed during the acute phase. Necrotic cells and cellular fragments were found in the lumen of the proximal tubules. Later, at day 21 (Figure 1I), numerous atrophic tubules were detected with a maximal degree of severity at day 35 (Figure 1J).

\section{Time course of fibrosis}

As observed in Figure 2, the renal mRNA level of TGF- 3 , a marker of fibrosis, significantly and progressively increased from day 10 to 35 in AA-treated rats (Figure 2A). On the other hand, there was no significant difference in the density nor distribution of the collagen components of the extracellular matrix, as stained by Sirius Red, from day 3 to 21. Collagen accumulated at day 35, mostly in OSOM and medullary rays, in the form of thickened basal membrane of altered PTECs and extensive fibrous deposits around necrotic tubules (Figures $2 \mathrm{C}$ and $\mathrm{D})$. Overall, the time course of PTEC lesions, atrophy, and fibrosis is similar to what has been described in this AAN model $[3,5,7]$.

\section{HA density and distribution}

In control or SHAM rats, HA was distributed in the three areas of the kidney (cortex, OSOM, and inner stripe of the outer medulla ISOM ) with a strong cortico-papillary gradient (Figure $3 \mathrm{~A})$. In the normal cortex, HA concentration was very low and mainly concentrated in the connective tissue surrounding large blood vessels. A thin frame of HA staining was also present in the interstitial matrix around a few glomeruli or occasionally in the peritubular spaces (Figure 3A). In OSOM, as in the cortex, HA was
A
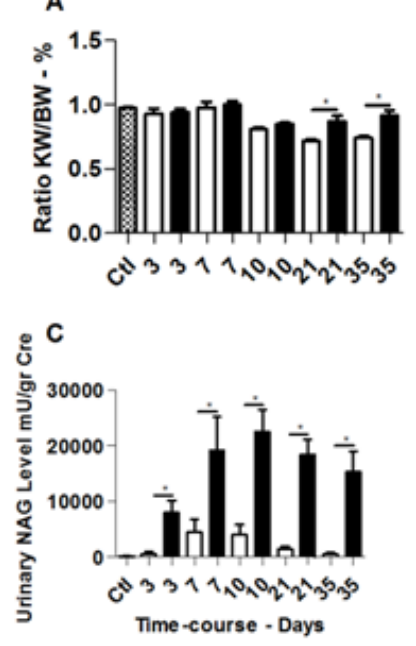

B
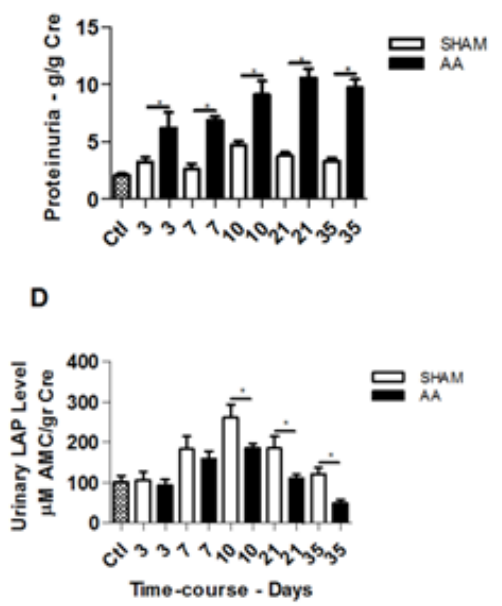

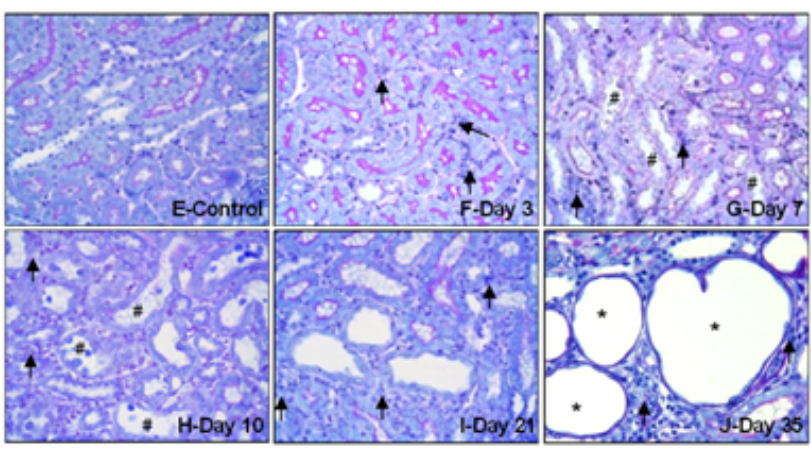

Figure 1: Time course of TI lesions. Ratio of kidney weight to body weight demonstrates kidney hypertrophy at days 21 and 35 (A). Urinary protein level indicates a rapid elevation in AA group as soon as day 3 (B). Urinary $N$-acetyl- $B$-D-glucosaminidase (NAG) level in AA group shows a significant increase by day 3 and remains elevated during the 35 days period (C). Decreased urinary leucine aminopeptidase (LAP) level (D) attests tubular damage. Representative photographs of tissue injury (x200) at different time points: control condition (E); day 3 - increase of interstitial cells (F-arrow); day 7 - patchy zones of necrotic proximal tubular epithelial cells (PTECs) (\#) associated with significant cell infiltration (arrow) (G); day 10-increase in necrotic PTECs (H); day 21 - increased tubular necrosis with appearance of atrophic tubules and significant cell infiltration (arrow)- (I); day 35 - extended zone of atrophic tubules (star) associated with infiltration of interstitial cells (arrow) - $(\mathrm{J})$. Values are means \pm SEM. $\mathrm{N}=6$ in each group. ${ }^{*} \mathrm{p} \leq 0.05$ versus SHAM rat at corresponding time-point. 

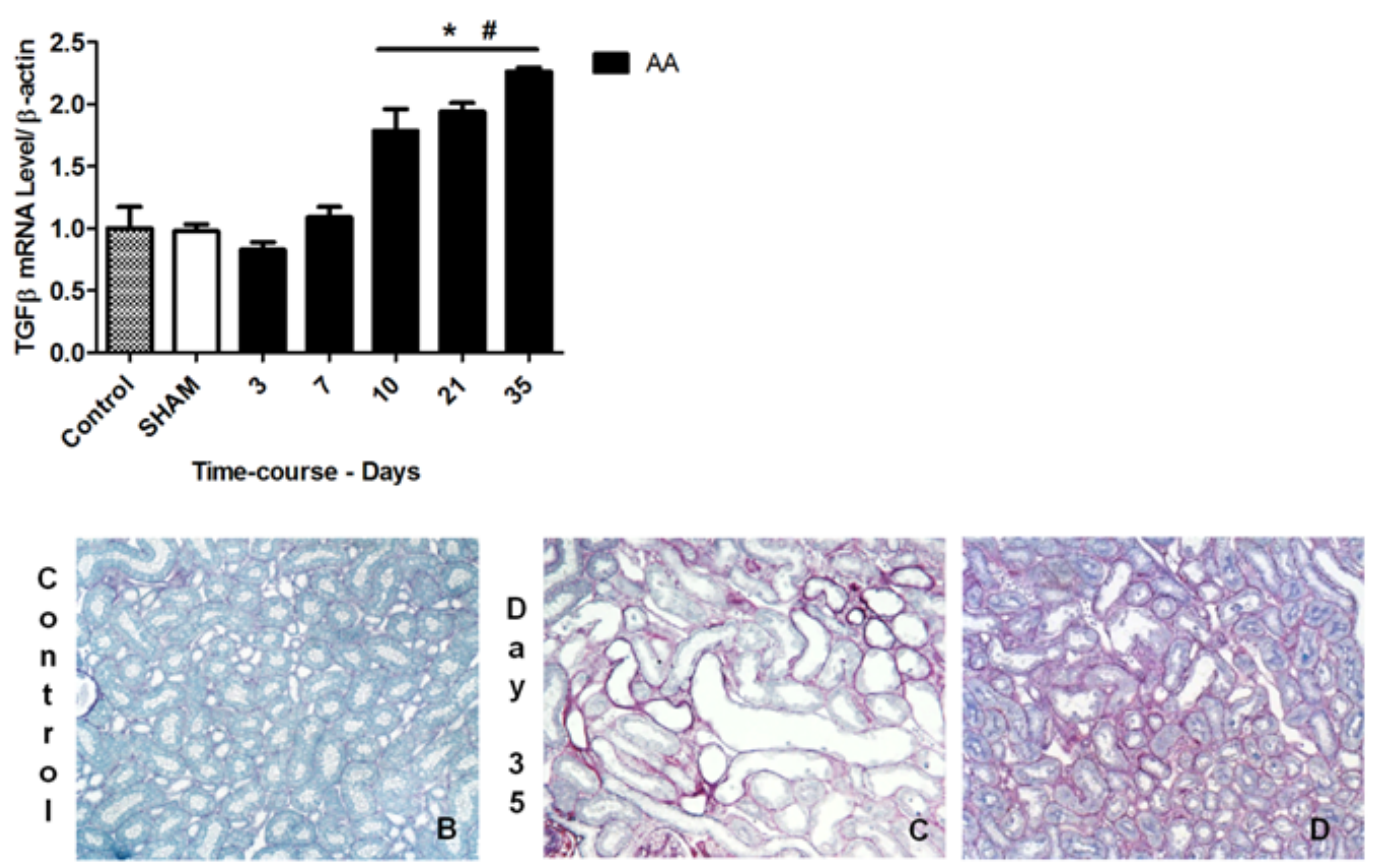

Figure 2: Time course of fibrosis progression. Quantitative real-time PCR of TGF- $B$ mRNA was performed with kidney tissue from all experimental groups (A). Representative photographs of Sirius red staining in OSOM in control rat (B) and at day 35 (C\&D) (x200). Values are means \pm SEM. $N=6$ in each group. ${ }^{*} p \leq 0.05$ versus SHAM rat at corresponding time-point.

found mostly in specific clusters around blood vessels and as a weak discontinuous network between tubular structures (Figure 3B). In ISOM, a continuous HA network extended between all tubular and vascular structures (Figure $3 \mathrm{~A}$ ).

AA intoxication induced significant changes in the distribution and density of HA in the renal tissue. In AA-treated rats, HA increased progressively and markedly in the extracellular matrix of outer medulla and medullary rays along tubular damages. During the acute phase, a highly HA-enriched matrix developed in the patchy zones of tubular necrosis (Figure 3C-F). Later, during the chronic phase, HA progressively invaded the whole interstitium and was associated with atrophic and undifferentiated tubules (Figure 3G-J). HA density was also associated with interstitial cell infiltration during the acute phase and with fibrotic areas in the chronic phase. As illustrated in Figure 3K, the time-course of HA density in the outer medulla showed a gradual and significant increase throughout the one-month observation period.

\section{Time-course of CD44 expression}

In control or SHAM rats (Figure 4A-C), CD44 immunoreactivity was mostly present on the basal membrane of collecting ducts. In ISOM, the vast majority (98 \%) of collecting ducts expressed CD44 at their basal pole (Figure 4C). In addition, the thin descending limbs of Henle's loop were also uniformly positive for CD44. In the cortex and OSOM, a few collecting ducts expressed CD44 (Figure 4A\&B). CD44 was also present, to a lesser extent, on isolated cells in proximal tubules and on some glomerular cells (Figure 4A). In all areas, a very small amount of CD44+ cells was observed within the interstitium (Figure $4 \mathrm{~A} \& \mathrm{~B})$

In AA-treated rats, at day 3, the density of CD44+ cells rose within the interstitium (Figure 4D-F). These cells were either isolated or concentrated in focal areas, between apparently intact tubules. At this time point, tubular CD44 expression was restricted to collecting ducts. At days 7 and 10 (Figure 4G-I), patchy zones of PTEC necrosis were observed together with a significant increase in CD44 expression. CD44 staining was now abundant on both interstitial cells around the damaged tubules and along apical and basolateral plasma membranes of necrotic PTECs. During the chronic phase, at days 21 (Figure 4J-L) and 35 (Figure 4M-O), TI injury extended dramatically and CD44 density remained high in both interstitium and atrophic or undifferentiated tubules.

Figure 4P illustrates the overall time course of CD44 immunostaining while Figure 4Q illustrates the number of CD44positive cells in the interstitium in OSOM. Higher magnified photographs of CD44 expression on interstitial cells are shown in Figure 4R-W. In addition to a fibroblast-like phenotype, a subpopulation of strongly positive flat cells was found, forming a cuff surrounding the tubules (Figure $4 \mathrm{U}-\mathrm{W}$ ). These CD44+ cells were further characterized.

\section{Characterization of CD44+ cells}

PCNA: As it has been already demonstrated in our previous study [7], PCNA+ tubular and interstitial cells were seen in the renal tissue with a maximal expression during the acute AAN phase (1 to 10 days). As illustrated in Figure 5A-D, PCNA-positive cells emerged in significant numbers three days after AA intoxication (Figure $5 \mathrm{~A}$ ), to reach a maximum value at day 10 Figure $5 \mathrm{~B}$ and progressively decreased at days 21 and 35 Figure 5C. Here, we showed that a significant proportion of PCNA+ cells was also $\mathrm{CD} 44+$, and thus proliferating, at days 7 to 21 with a peak at day 10 (Figure 5E-H). These proliferative cells were observed in both tubular and interstitial compartments. As 

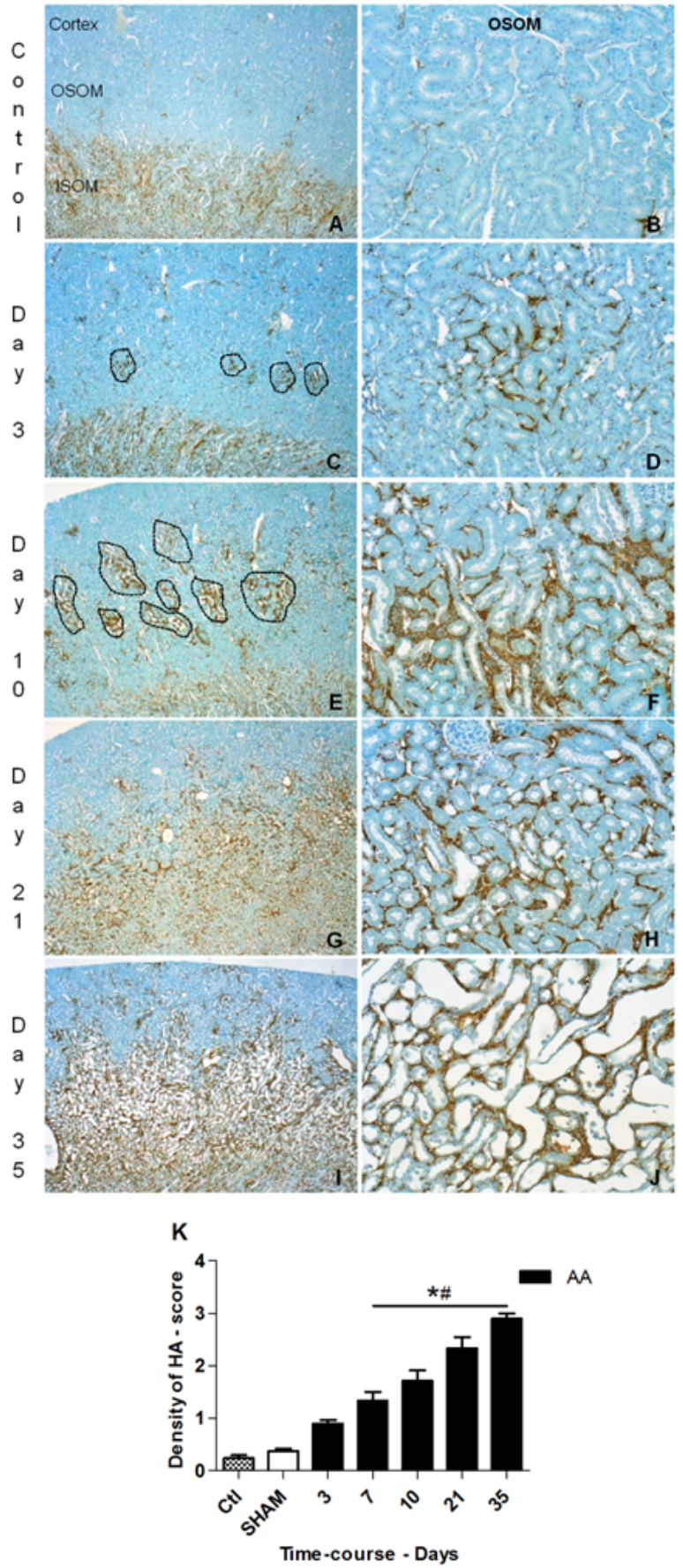

Figure 3: HA density and distribution. Representative photomicrographs of $H A$ labelling in renal tissue of control rats (A: $x 40-B: \times 200)$ or AA-treated rats at days 3 (C: x40 - D: x200), 10 (E: x40 - F: x200), 21 (G: x40 - H: x200), and day 35 (I: $x 40-\mathrm{J}: \mathrm{x200)}$. Dotted line $(C \& D)=$ area of necrotic PTEC. Semiquantitative scoring of HA staining density $(K)$ in control, SHAM- or AA-treated rats at different time points after treatment.

Values are means \pm SEM. $N=6$ in each group. ${ }^{*} p \leq 0.05$ versus SHAM; \#p $\leq$ 0.05 versus control. illustrated in (Figure 5 E-G), CD44 (red) was expressed on the apical and basolateral membrane of the cells while PCNA (green) was located in the nuclei. The onset of this proliferation is concomitant with the acute tubular necrosis (Figure 1F-H), suggesting an attempt of PTECs to regenerate Vimentin.

While vimentin was only expressed in few interstitial cells in control or SHAM rats (Figure 6A), its expression rose gradually and significantly throughout the observation period (Figure 6C). At day 3 , while no obvious sign of tubular expression was observed, vimentin was expressed in interstitial cells mostly located in the outer medulla and medullary rays (Figure 6B). At days 7 and 10, the proportion of vimentin+ cells significantly rose in PTEC area (Figure 6D). Moreover, damaged PTEC began to express vimentin, demonstrating their dedifferentiated phenotype (Figure 6D). During the chronic phase, both the dedifferentiated PTECs and an impressive proportion of interstitial cells expressed vimentin (Figure 6E\&F). Vimentin/CD44 double staining revealed that after 10 days of AA intoxication, $75.6 \pm 2.0$ $\%$ of CD $44+$ cells were also vimentin+ (Figure 6I). This observation was confirmed at subsequent time-points. At day 35, for instance, atrophic tubules were colonized by both markers (Figure 6J-L).

$\alpha$-SMA. In control or SHAM rats, $\alpha$-SMA localization was limited to the media of vessels (Figure 7A). However, a small amount of a-SMA-positive cells was also located in the interstitial space. At day 3 , a few clusters of $\alpha$-SMA-positive interstitial cells were detected around tubules in the cortex and OSOM Figure 7B. Thereafter, the density of positive cells rose progressively and significantly in the zones of necrotic PTEC (Figure 7D\&E). At day 35, a-SMA-positive cells gathered around atrophic tubules (Figure 7F). Altogether, $\alpha$-SMA was never expressed at a tubular level and acquisition of the myofibroblast phenotype predominated during the fibrotic phase. (Figure 7C) illustrates the relative area occupied by a-SMA in the outer medulla over the course of the experiment.

Double fluorescent immunestaining for CD44 and a-SMA showed that only a small amount $(10.0 \pm 4.0 \%)$ of interstitial $\alpha$-SMA-positive cells were CD44-positive during the early phase (Figures 7G-H); that percentage increased at day $35(23.3 \pm 5.0 \%)$, when both markers coincided in the patchy zones of PTEC necrosis (Figures 7I-J).

CD133: In control or SHAM rats, CD133 was mostly expressed on the collecting ducts, in particular in ISOM (Figure $8 \mathrm{~B}$ ) and to a lesser extent in OSOM (Figure 8A). Eighty-three \% of the collecting ducts in ISOM expressed CD133 (Figure 8I) versus 35\% in OSOM (Figure $8 \mathrm{H}$ ). In addition, the brush border of $\mathrm{S} 1$ and $\mathrm{S} 2$ proximal tubules in the cortex was also positive for CD133 (not shown). In AA-treated rats, the proportion of CD133-positive collecting ducts did not significantly change throughout the study (Figure 8C-D and H-I). The expression of this stem cell marker was never observed in dedifferentiated PTECs. On the other hand, CD133-positive cells in the interstitium, mostly in OSOM (Figure 8C-insert), tended to increase during the course of the study although that increase was not statistically significant (Figure 8JK). Double immunostaining for CD133 and CD44 showed that $10 \%$ of collecting duct cells were positive for both markers at all stages (Figures $8 \mathrm{E}-\mathrm{G})$. However, none of the interstitial CD133-positive cell was CD44positive.

\section{Discussion}

Human AAN is a "pure" example of progressive TI nephritis leading to fibrosis and end-stage renal disease. Our group has unraveled several features of this disease using a specific rat model $[3,6,7]$, including the 
Citation: Decleves AE, Pozdzik A, Baudoux T, Habsch I, De Prez E, et al. (2013) CD44-Positive Cells and Hyaluronan are a Hallmark of a Rat Model of Aristolochic Acid Nephropathy. J Cytol Histol 4: 186. doi: 10.4172/2157-7099.1000186

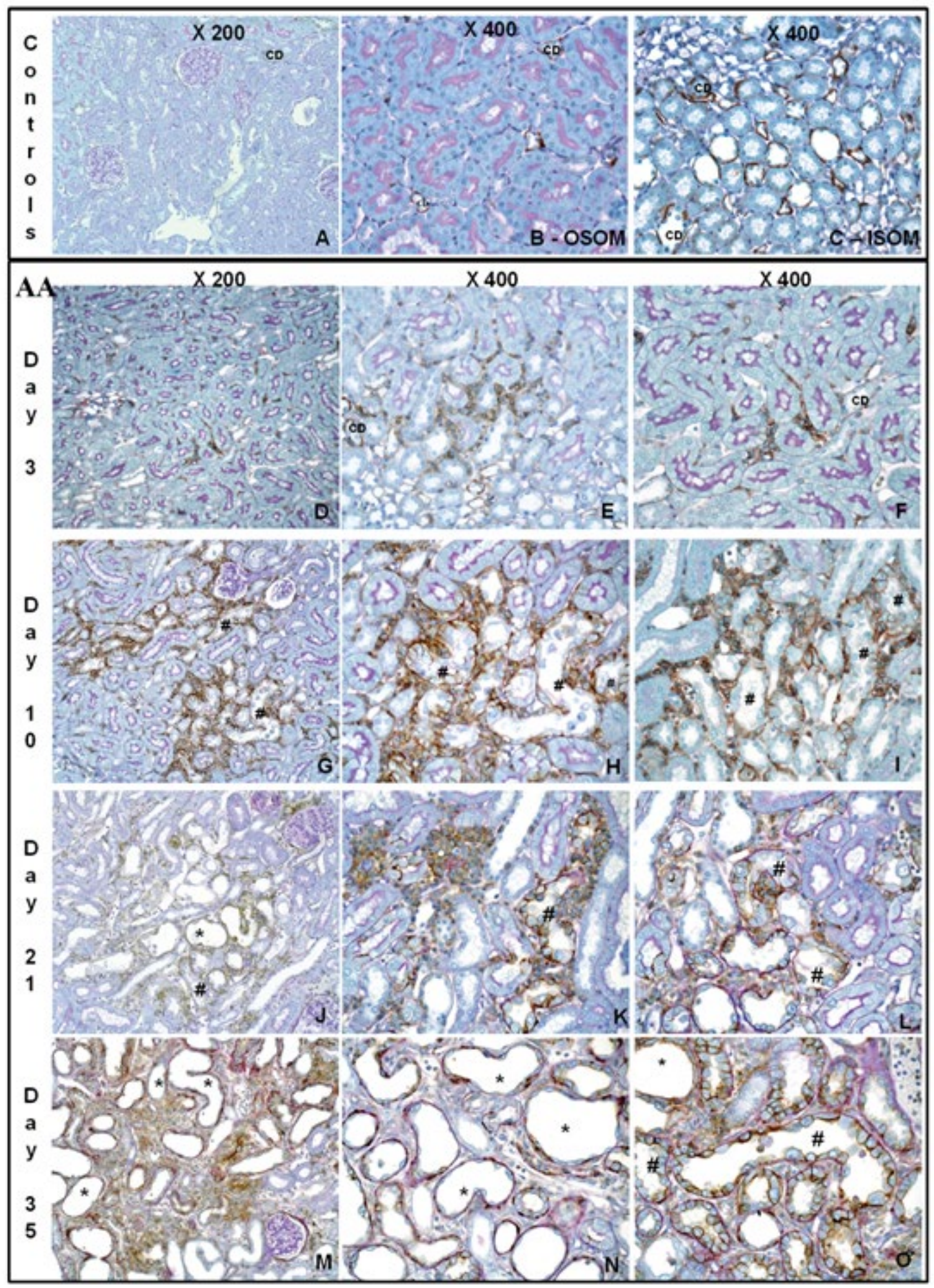

Figure 4A: Time course of $C D 44$ expression. Representative photomicrographs of $C D 44$ in renal tissue of control rat $(A=C o r t e x-O S O M, x 200$; $B=0 S O M \times 400$; $\mathrm{C}=\mathrm{ISOM}, \mathrm{x} 400)$ or AA-treated rats in OSOM at days 3 (D x200; E-F x400), 10 (G x200; H/I x400), 21 (J x200; K/L x400), and 35 (M x200; N-O x400). CD= collecting ducts; *=Atrophic tubules; \#= necrotic proximal tubular epithelial cells. 
$\mathbf{P}$

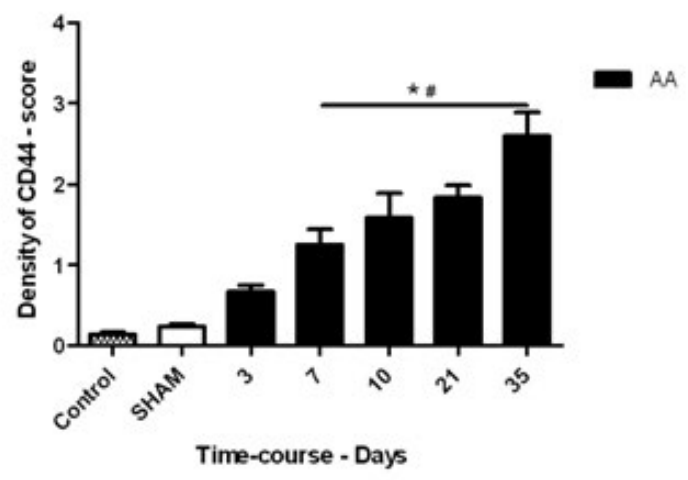

Q

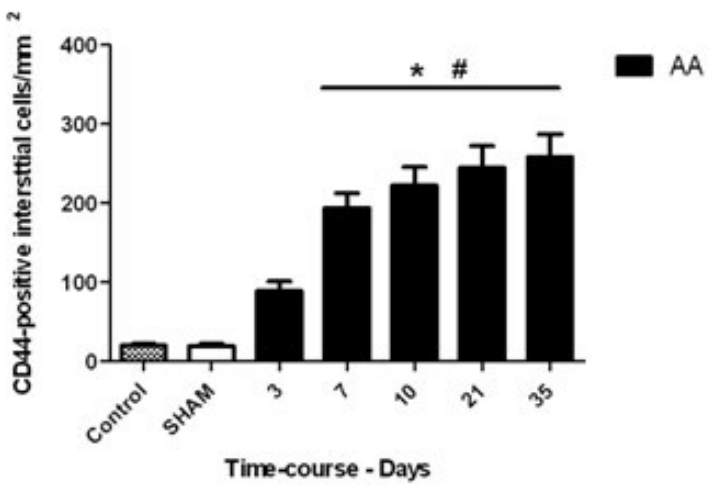

Magnified pictures of CD44 on interstitial cells $(\times 1000)$

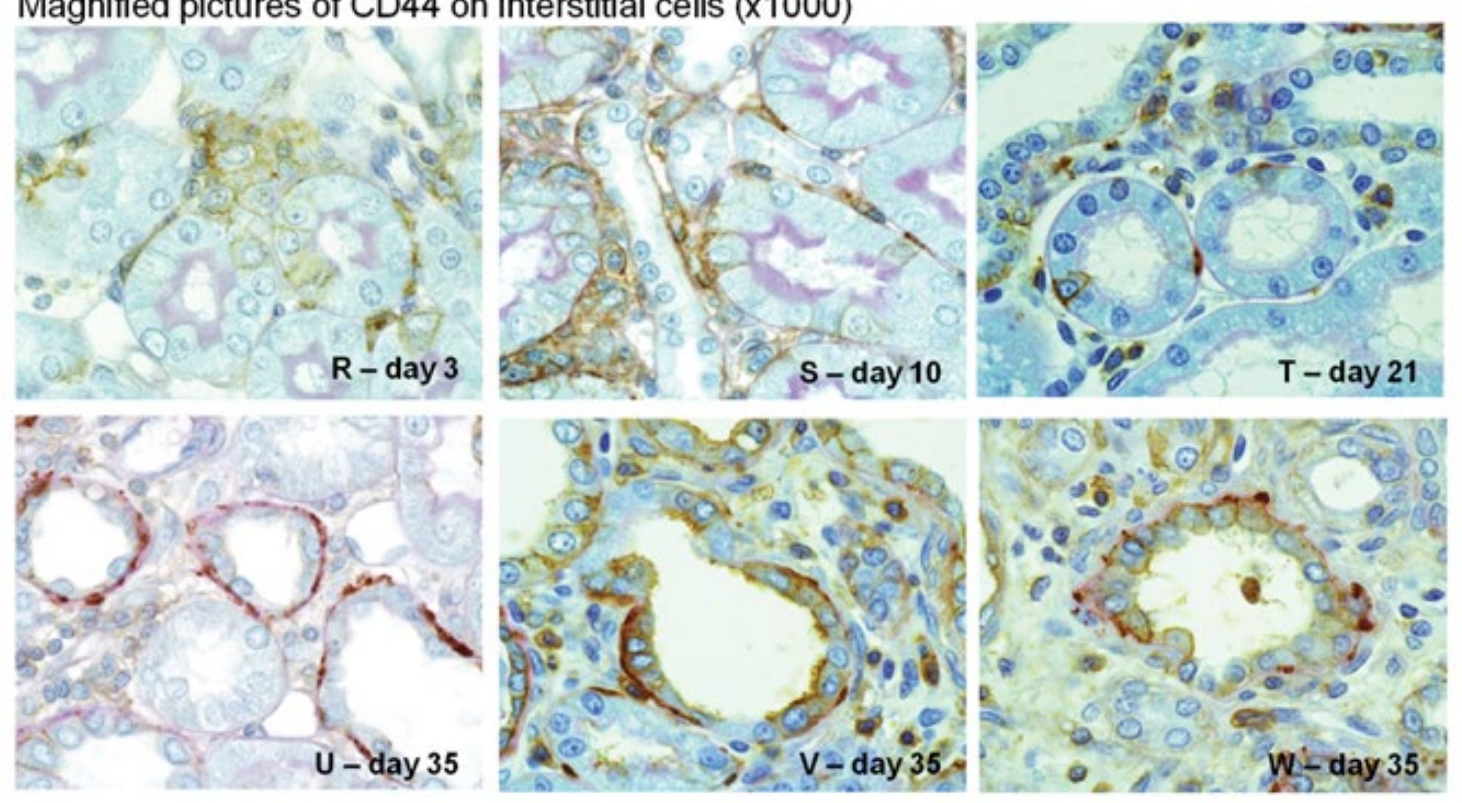

Figure 4B: Time course of CD44 expression. Representative photomicrographs of CD44 in renal tissue of control rat. P: Semi-quantitative scoring of CD44 immunostaining in OSOM in control, SHAM- or AA-treated rats at different timepoints after treatment. Q: Semi-quantitative analysis of CD44-positive interstitial cells in OSOM in control, SHAM- or AA-treated rats at different time-points after treatment. R-W: Representative magnified (x1000) photomicrographs of CD44 on interstitial cells in AA-treated rats at day $3(\mathrm{R})$, day $10(\mathrm{~S})$, day $21(\mathrm{~T})$ and day $35(\mathrm{U}-\mathrm{W})$. Values are means $\pm \mathrm{SEM}$. $\mathrm{N}=6$ in each group. * $\mathrm{p} \leq 0.05$ versus SHAM; \#p $\leq 0.05$ versus control.

presence of deficient tubular epithelium regeneration. Dedifferentiation markers such as vimentin were abundant in PTECs during the acute phase of AAN [7]. An imbalance between differentiation and proliferation was suggested as one causal mechanism of severe atrophy development.

In the current study, we demonstrate for the first time the temporal expression of CD44 and its major ligand, HA, in the rat model of AAN. CD44 and HA expressions increased dramatically and concomitantly throughout the course of the disease, in parallel with PETC necrosis and interstitial fibrosis. Both markers were tightly linked to the areas of TI lesions, suggesting a crosstalk between CD44 and HA, and between these markers and the AAN lesions. CD44 has been associated with regenerating cells in the liver and kidney $[8,10,12,20,21]$ but from the results of our study there is no sign that a lack of CD44 might be involved in the poor tubular regeneration.

CD44 is an early marker of AAN. While its expression in control kidneys was low and confined to the basal membrane of the collecting ducts cells and a few interstitial cells, strong CD44 signals appeared as soon as 3 days and continued to increase remarkably thereafter, especially in interstitial cells gathering around necrotic PTECs but also on damaged tubules. A large number of these CD44+ cells was PCNA+, suggesting a role of CD44 in the regeneration process of AAN. Indeed, Pozdzik et al. [7] demonstrated a significant increase of PCNA+ tubular and interstitial cells in a similar AAN model. This rise of proliferating cells was maximal during the acute AAN phase, suggesting an attempt of PTECs to regenerate. During the chronic phase, Pozdzik et al. [7] observed a decline of proliferating cells in PTECs concomitant with an increase of tubular atrophy. This latter demonstrated a defect in the 
Citation: Decleves AE, Pozdzik A, Baudoux T, Habsch I, De Prez E, et al. (2013) CD44-Positive Cells and Hyaluronan are a Hallmark of a Rat Model of Aristolochic Acid Nephropathy. J Cytol Histol 4: 186. doi: 10.4172/2157-7099.1000186

regenerative process of PTEC and a development of TI fibrosis, which were also observed in the present study. Indeed, PCNA/CD44+ cells were maximal at day 10 after AA intoxication and progressively decrease thereafter. However, in our study, CD44 density remained very high during the chronic fibrotic phase, possibly in relation with sustained TI injury. Previously, we reported the involvement of HA and CD44 during the recovery phase of a renal ischemic insult [8]. We showed that CD44 was upregulated in regenerative PTECs concomitantly with an increase in HA density [8]. Therefore, the CD44-HA pair seems to be an intrinsic component of many renal diseases, with actions ranging from the repair process to late fibrosis development. During nephrogenesis, it has been shown that the HA-CD44 couple is critically involved in the formation and branching of the ureteric tree [22]. Similarly, the absence of CD44 worsened tubular injury consecutive to ureteral obstruction [14] as well as lung injury after bleomycin administration [16]. However, a study using CD44 knockout mice subjected to mild bilateral renal ischemia-reperfusion injury revealed that tubular regeneration was not altered and that kidneys recovered normal physiological functions [23]. Therefore, CD44 may not be crucial for all renal disease recoveries, depending on the severity of the lesions. A murine model may be useful to test the hypothesis that CD44 deficiency could lead to more severe tubular atrophy in AAN.

On the other hand, the implication of HA-CD44 in the progression of renal fibrosis has been highlighted in e.g. experimental glomerulonephritis [11] and cyclosporin nephropathy [24]. In the current model of AAN both CD44 and HA are strongly linked to fibrotic islets. What is the most likely link between CD44-HA and renal fibrosis?

To answer that question, our results first showed that only a small population of CD44+ cells co-expressed $\alpha$-SMA, a marker of myofibroblasts, which are central to fibrogenesis. The best demonstration that HA-producing myofibroblasts and CD44 are principal actors in fibrosis has recently been provided by $\mathrm{Li}$ et al. [25]. These authors
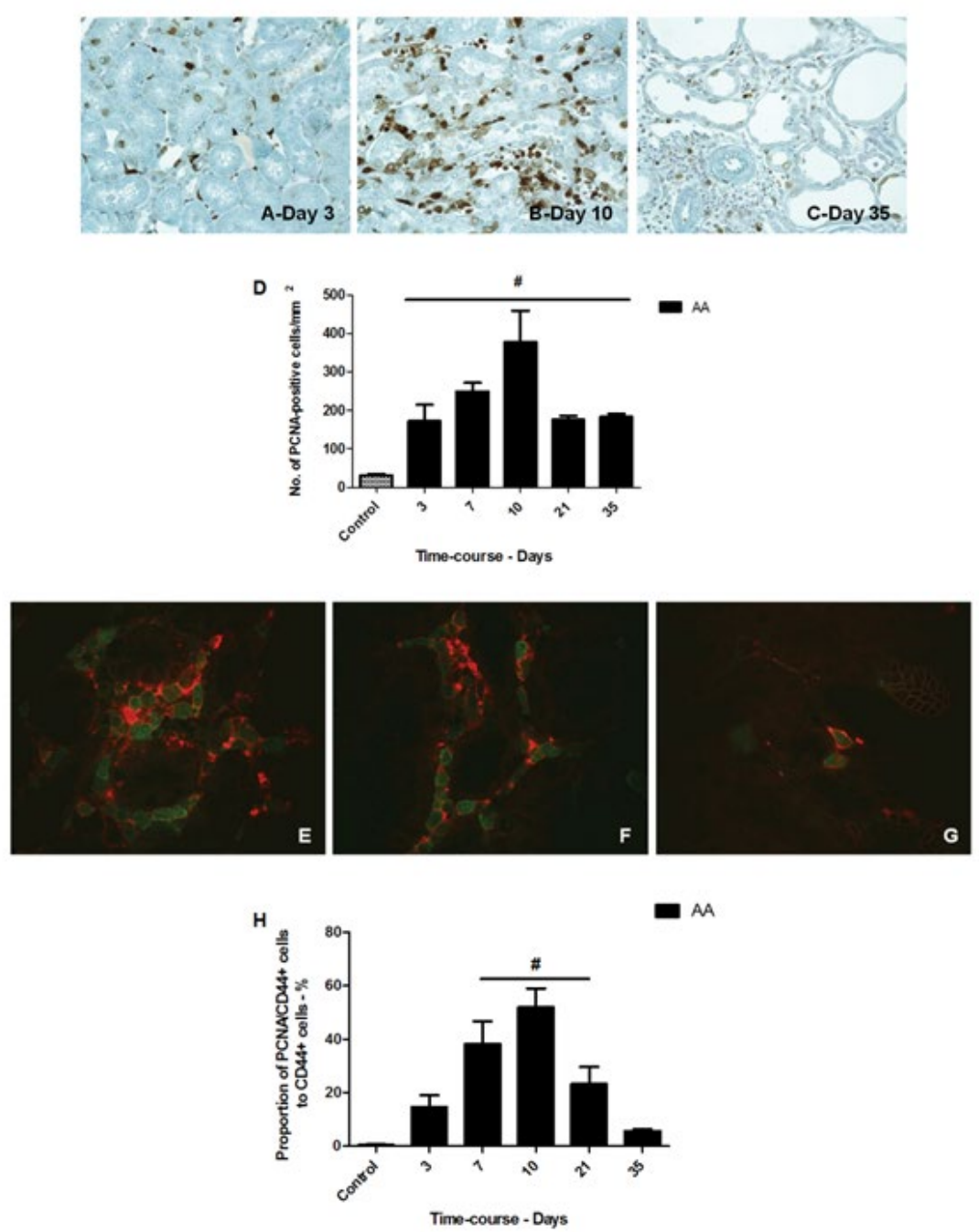

Figure 5: Representative photomicrographs of PCNA-positive cells in the tubules and the interstitium (x400) in AA-treated rats at day 3 (A), day 10 (B) and day 35 (C). Semiquantitative analysis of PCNA-positive staining in AA-treated rats at different time 3 points after treatment (D). Representative photomicrographs of double immunostaining (x1000, arrow) for CD44 and PCNA in AA-treated rats at day 10 (E-G). As shown, CD44 (red) was localized on the basolateral and apical cellular membrane while PCNA labeled the cellular nuclei (green). Semi-quantitative analysis of CD44/PCNA-positive staining in tubular and interstitial cells in control or AAtreated rats at different time points after treatment $(\mathrm{H}) . \# p \leq 0.05$ versus control 
Citation: Decleves AE, Pozdzik A, Baudoux T, Habsch I, De Prez E, et al. (2013) CD44-Positive Cells and Hyaluronan are a Hallmark of a Rat Model of Aristolochic Acid Nephropathy. J Cytol Histol 4: 186. doi: 10.4172/2157-7099.1000186

have shown that CD44 is upregulated after bleomycin-induced lung injury in transgenic mice that overexpress the HA synthase HAS2 in myofibroblasts. In these mice, the administration of anti-CD44 blocking antibodies prevents the accumulation of collagen. On the contrary, in the rat AAN model, $\alpha$-SMA expression is a late event limited to the chronic phase and the co-localization of $\alpha$-SMA with CD44 is weak. Although some CD44+ cells may possess a fibroblastic phenotype, an important role of the HA-CD44 pair in fibrogenesis appears unlikely.

A second hypothesis is that CD44+ cells are mostly regenerative, stem cell-like cells in AAN. Indeed, the contribution of resident, or even infiltrating, stem/progenitor cells in renal regeneration and repair processes has been reported [26-28]. CD133+ cells derived from normal kidney tissue have been shown to differentiate into epithelial and endothelial cells in vitro [29]. Ye et al. demonstrated that CD133+ stem/progenitor cells residing in the human renal cortex and medulla exhibit a proliferative capacity after acute tubular necrosis [30]. In normal human kidney, CD133 seems to be mostly located in the parietal layer of Bowman capsule, brush border of PTEC, collecting ducts, and interstitium [27,30,31]. In many forms of experimental kidney injury, an upregulation of CD133 was reported [28,30,32]. However, this was not reproduced in our rat model of AAN since CD133 was mostly expressed in the collecting duct cells. Moreover, the co-expression of CD44 and CD133 revealed that only 10\% of CD44+ cells are double-labeled in both control and AA-treated rats. In addition, we did not observe any evidence of CD133 expression in damaged or dedifferentiated PTEC. Overall, we do not believe that CD44 is a strong marker of stem/progenitor cells involved in renal tissue repair in AAN.

A third hypothesis is that a majority of CD44+ cells are mesenchymallike cells. This is exactly what we found using vimentin as a recognized marker of mesenchymal cells and cell differentiation. Previous studies, focusing on ischemic kidney injury, have demonstrated a transient upregulation of vimentin in dedifferentiated S3 segment of proximal tubules [33,34]. We confirm there is a massive accumulation of CD44+/ vimentin+ cells throughout the period of AA injections. These cells are not confined to the interstitial compartment but also belong to damaged tubules, suggesting a role of CD44 in unmasking the dedifferentiation
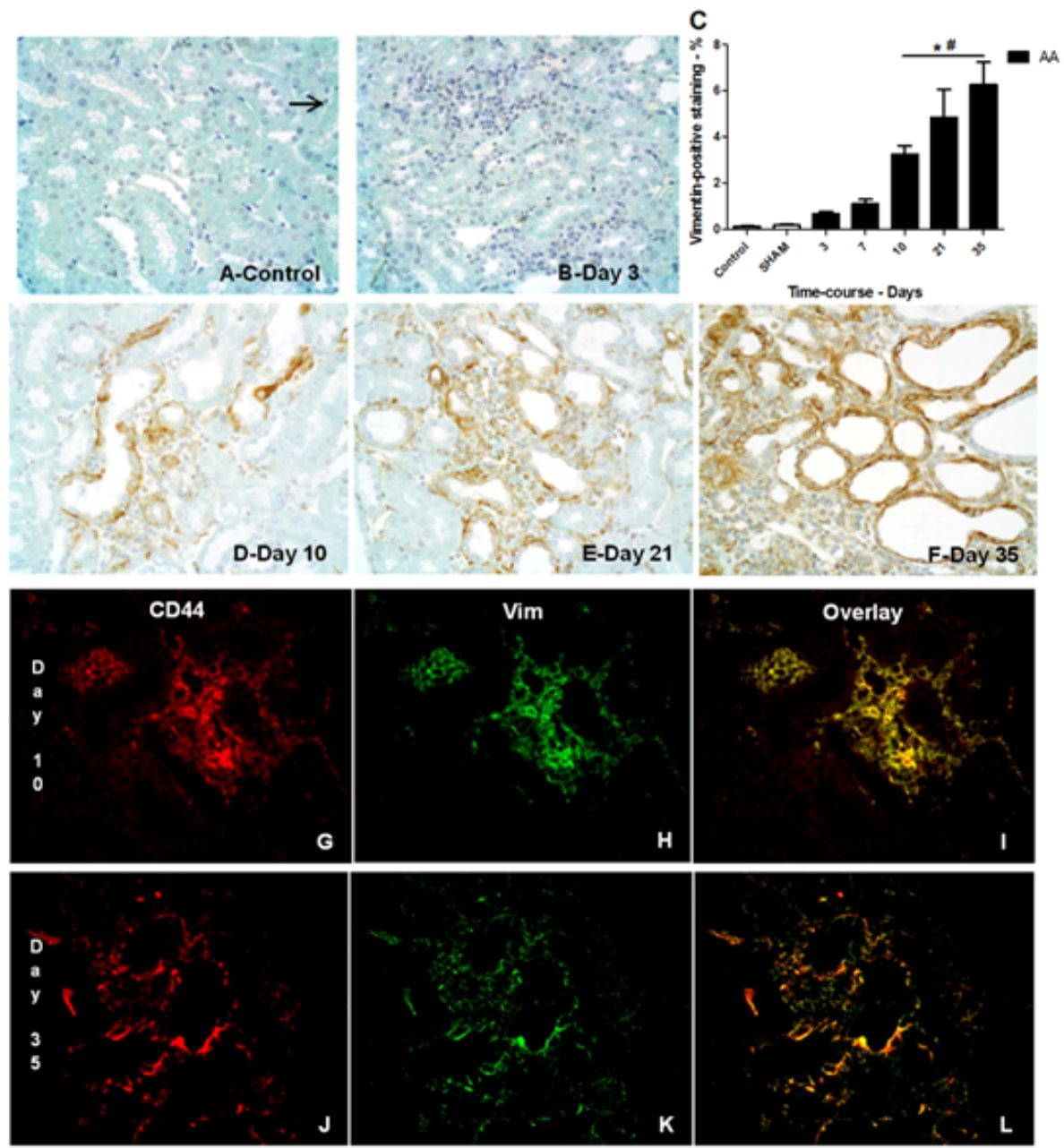

Figure 6: Representative photomicrographs of vimentin (x400) in renal tissue of control rat (A, arrow) or $A A$-treated rats at days 3 (B), 10 (D), 21 (E), and day $35(F)$. Semiquantitative analysis of vimentin-positive staining in control, SHAM- or AA-treated rats at different time-points after treatment (C). Double immunostaining (x400) for CD44 (red (G-J)) and vimentin (green (H-K)) in AA-treated rats at day 10 (overlay I) and day 35

(overlay L). ${ }^{*} p \leq 0.05$ versus SHAM; \#p $\leq 0.05$ versus control 
Citation: Decleves AE, Pozdzik A, Baudoux T, Habsch I, De Prez E, et al. (2013) CD44-Positive Cells and Hyaluronan are a Hallmark of a Rat Model of Aristolochic Acid Nephropathy. J Cytol Histol 4: 186. doi: 10.4172/2157-7099.1000186
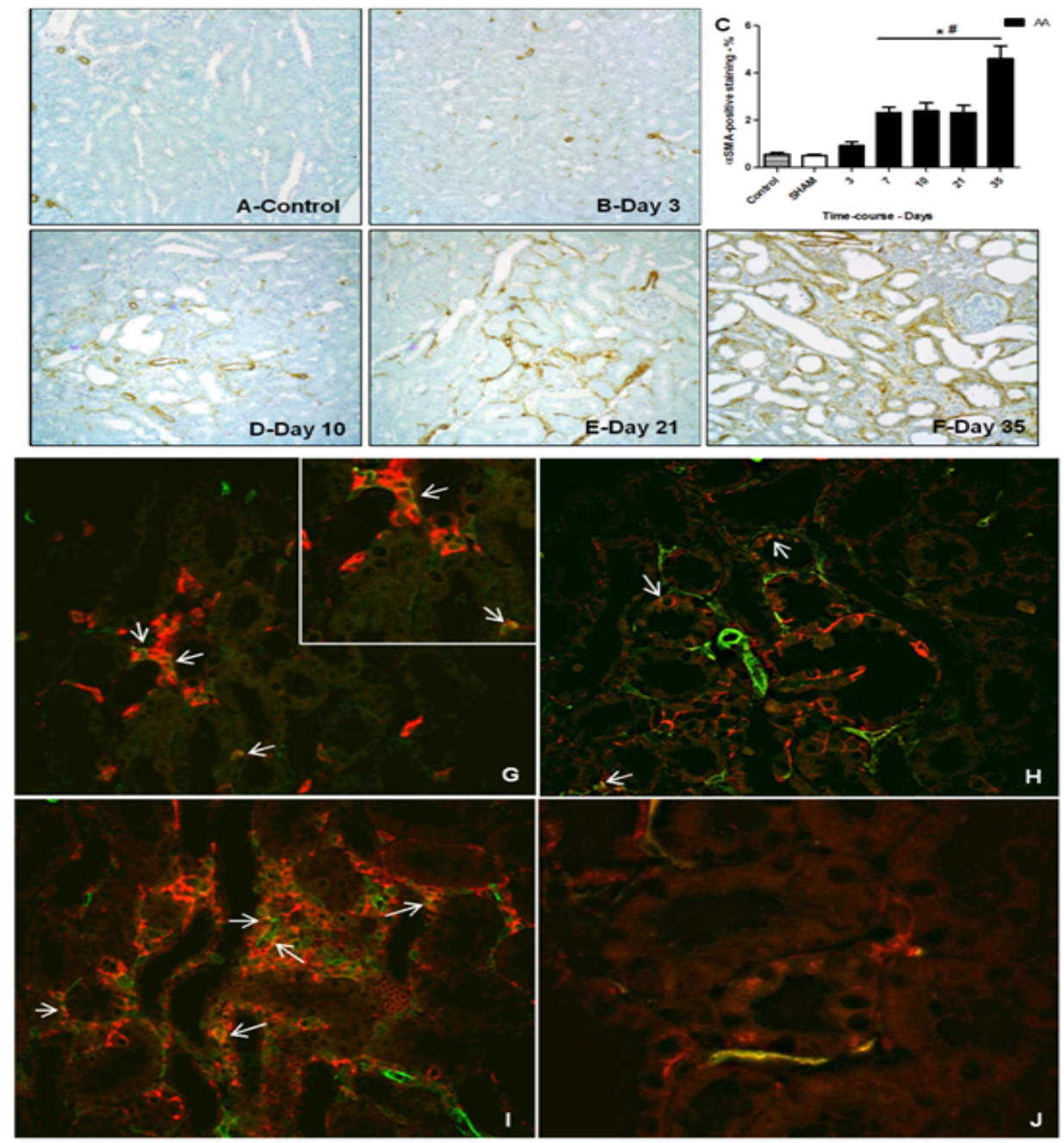

Figure 7: Representative photomicrographs of aSMA (x200) in renal tissue of control rat (A) or AA-treated rats at days 3 (B), 10 (D), 21 (E), and day 35 (F). Semiquantitative analysis of $\alpha$-SMA-positive staining in control, SHAM- or AA-treated rats at different time-points after treatment (C). Double immunostaining for aSMA (green) and CD44 (red) (arrowhead) in AA-treated rats at day 10 ( $\mathrm{G}, \mathrm{H} \times 400+$ insert to better illustrate the co-localization) and at day 35 (I, x400 - J, x1000). * $\mathrm{p} \leq 0.05$ versus SHAM; \#p $\leq 0.05$ versus control.

process. In normal conditions of regeneration, the restoration of brush border is accompanied by a loss of CD44 and vimentin markers $[8,33,34]$. The persistence of these markers at the late stage of the AAN model may signal factors interfering with the recovery phase such as sustained interstitial inflammation or an irremediable profibrotic environment underscored by high TGF- $\beta$ and $\alpha$-SMA expressions. In conclusion, strong activation of the HA-CD44 axis in AAN may signal a continuous attempt by kidney cells to dedifferentiate and regenerate the normal tubular structure through the mesenchymal-like phenotype. These attempts may fail due to the uninterrupted exposure to toxic AA.

\section{Conclusions}

Aristolochic acid nephropathy is a progressive tubulo-interstitial nephritis. AA-induced nephropathy consists in a biphasic evolution with an acute phase (3-10 days) characterized by the impairment of the proximal tubules associated with proteinuria followed by a chronic phase (after 14 days) characterized by a progressive development of the interstitial fibrosis. Nevertheless, signs of tubular regeneration during the acute phase were previously shown [7]. Similarly to our data, a transient decrease in proximal tubular enzymuria (LAP) was observed along with a transient increase in proliferating $(\mathrm{PCNA}+)$ cells reflecting an attempt of PTEC regeneration. In our study, we demonstrated the temporal expression of CD44 and hyaluronan in the rat model of aristolochic acid nephropathy. We highlighted an early and sustained activation of the HA-CD44 axis along with impaired PTEC regeneration as confirmed by the localization of CD44 on proliferative cells as well as the high prevalence of mesenchymal-like phenotype in tubular structures. However, the regenerative process failed, probably due to the sustained toxic exposure to AA, resulting in an irreversible proximal tubular atrophy and TI fibrosis.

\section{Acknowledgments}

This work was supported by grants from the Erasme Foundation (Erasme hospital, Brussels, Belgium) and the Fonds National de la Recherche Scientifique Medicale (Belgium). This work was presented as a poster at the Benelux Kidney Meeting, Eindhoven, The Netherlands, on October $11^{\text {th }}, 2012$. 


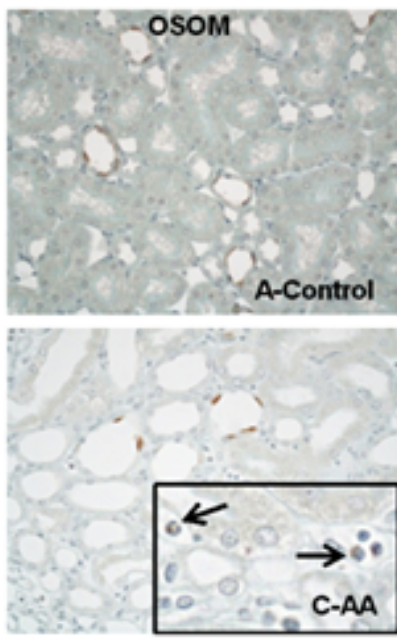

H
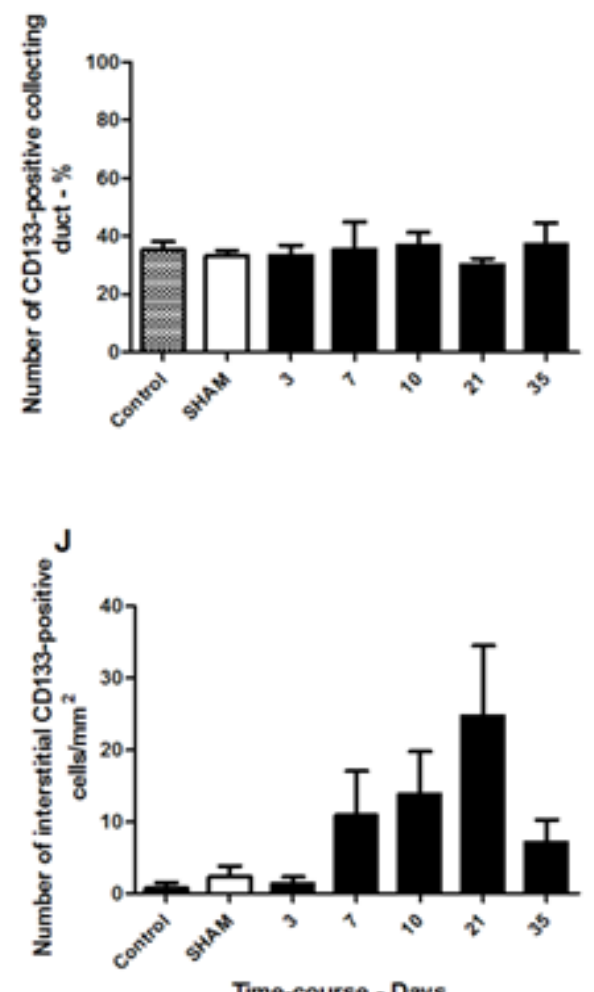

Time-course - Days

ISOM
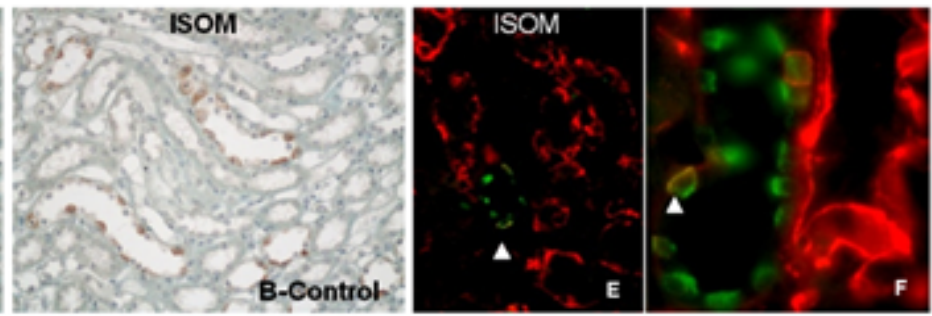

D-AA

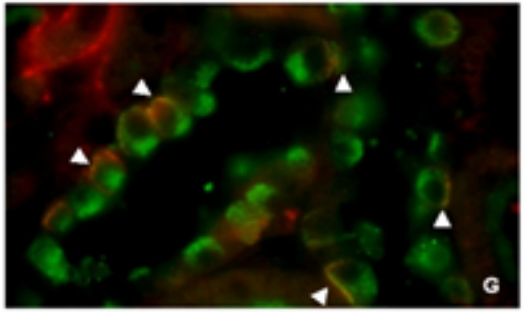

1

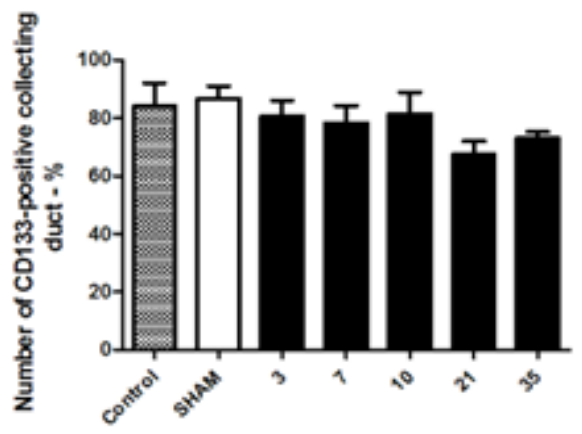

K

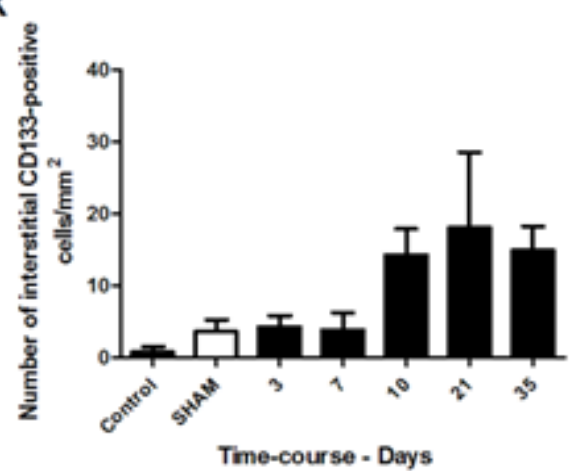

Figure 8: Representative photomicrographs of CD133 (x400) in renal tissue of control rat (OSOM, A - ISOM, B) or AA-treated rats at day 21 (OSOM, C - ISOM, D). The arrow in the insert (C) shows the CD133-positive cells in the interstitium. Double immunostaining for CD133 (green) and CD44 (red) in AA-treated rats at day 21 (E, x400; F-G, x1000). Semi-quantitative analysis of CD133-positive staining in the collecting ducts (OSOM, H - ISOM, I) and in the interstitium (OSOM, J - ISOM, K) for control, SHAM- or AA-treated rats at different time points after treatment.

\section{References}

1. Cosyns JP, Jadoul M, Squifflet JP, De Plaen JF, Ferluga D, et al. (1994) Chinese herbs nephropathy: a clue to Balkan endemic nephropathy? Kidney Int 45: 1680-1688

2. Vanherweghem JL, Depierreux M, Tielemans C, Abramowicz D, Dratwa M, et al. (1993) Rapidly progressive interstitial renal fibrosis in young women: association with slimming regimen including Chinese herbs. Lancet 341: $387-$ 391.
3. Pozdzik AA, Salmon IJ, Husson CP, Decaestecker C, Rogier E, et al. (2008) Patterns of interstitial inflammation during the evolution of renal injury in experimental aristolochic acid nephropathy. Nephrol Dial Transplant 23: 2480 2491.

4. Debelle FD, Vanherweghem JL, Nortier JL (2008) Aristolochic acid nephropathy a worldwide problem. Kidney Int 74: 158-169.

5. Lebeau C, Debelle FD, Arlt VM, Pozdzik A, De Prez EG, et al. (2005) Early proximal tubule injury in experimental aristolochic acid nephropathy: functional 
Citation: Decleves AE, Pozdzik A, Baudoux T, Habsch I, De Prez E, et al. (2013) CD44-Positive Cells and Hyaluronan are a Hallmark of a Rat Model of Aristolochic Acid Nephropathy. J Cytol Histol 4: 186. doi: 10.4172/2157-7099.1000186

and histological studies. Nephrol Dial Transplant 20: 2321-2332.

6. Nortier JL, Deschodt-Lanckman MM, Simon S, Thielemans NO, de Prez EG, et al. (1997) Proximal tubular injury in Chinese herbs nephropathy: monitoring by neutral endopeptidase enzymuria. Kidney Int 51: 288-293.

7. Pozdzik AA, Salmon IJ, Debelle FD, Decaestecker C, Van den Branden C, et al. (2008) Aristolochic acid induces proximal tubule apoptosis and epithelial to mesenchymal transformation. Kidney Int 73: 595-607.

8. Declèves AE, Caron N, Nonclercq D, Legrand A, Toubeau G, et al. (2006) Dynamics of hyaluronan, CD44, and inflammatory cells in the rat kidney after ischemia/reperfusion injury. Int J Mol Med 18: 83-94.

9. Asselman M, Verhulst A, De Broe ME, Verkoelen CF (2003) Calcium oxalate crystal adherence to hyaluronan-, osteopontin-, and CD44-expressing injured/ regenerating tubular epithelial cells in rat kidneys. J Am Soc Nephrol 14: 31553166 .

10. Asselman M, Verhulst A, Van Ballegooijen ES, Bangma $\mathrm{CH}$, Verkoelen CF, et al. (2005) Hyaluronan is apically secreted and expressed by proliferating or regenerating renal tubular cells. Kidney Int 68: 71-83.

11. Jun Z, Hill PA, Lan HY, Foti R, Mu W, et al. (1997) CD44 and hyaluronan expression in the development of experimental crescentic glomerulonephritis. Clin Exp Immunol 108: 69-77.

12. Lewington AJ, Padanilam BJ, Martin DR, Hammerman MR (2000) Expression of CD44 in kidney after acute ischemic injury in rats. Am J Physiol Regul Integr Comp Physiol 278: R247-254.

13. Rouschop KM, Roelofs JJ, Sylva M, Rowshani AT, Ten Berge IJ, et al. (2006) Renal expression of CD44 correlates with acute renal allograft rejection. Kidney Int 70: 1127-1134.

14. Rouschop KM, Sewnath ME, Claessen N, Roelofs JJ, Hoedemaeker I, et al. (2004) CD44 deficiency increases tubular damage but reduces renal fibrosis in obstructive nephropathy. J Am Soc Nephrol 15: 674-686.

15. McKallip, R.J., et al. (2005) Role of CD44 and its v7 isoform in staphylococcal enterotoxin B-induced toxic shock: CD44 deficiency on hepatic mononuclear cells leads to reduced activation-induced apoptosis that results in increased liver damage. Infect Immun 73: 50-61.

16. Teder P, Vandivier RW, Jiang D, Liang J, Cohn L, et al. (2002) Resolution of lung inflammation by CD44. Science 296: 155-158

17. Stagg J, Galipeau J (2007) Immune plasticity of bone marrow-derived mesenchymal stromal cells. Handb Exp Pharmacol : 45-66.

18. Debelle FD, Nortier JL, De Prez EG, Garbar CH, Vienne AR, et al. (2002) Aristolochic acids induce chronic renal failure with interstitial fibrosis in saltdepleted rats. J Am Soc Nephrol 13: 431-436.

19. Nonclercq D, Liénard V, Zanen J, Laurent G, Toubeau G (2002) Phenotypic variations and dynamic topography of transformed cells in an experimental model of diethylstilbestrol-induced renal tumour in male Syrian hamster. Histochem J 34: 487-497.
20. Herrera MB, Bussolati B, Bruno S, Morando L, Mauriello-Romanazzi G, et al (2007) Exogenous mesenchymal stem cells localize to the kidney by means of CD44 following acute tubular injury. Kidney Int 72: 430-441.

21. Chiu CC, Sheu JC, Chen CH, Lee CZ, Chiou LL, et al. (2009) Global gene expression profiling reveals a key role of CD44 in hepatic oval-cell reaction after 2-AAF/CCl4 injury in rodents. Histochem Cell Biol 132: 479-489.

22. Pohl M, Sakurai H, Stuart RO, Nigam SK (2000) Role of hyaluronan and CD44 in in vitro branching morphogenesis of ureteric bud cells. Dev Biol 224: 312325

23. Rouschop KM, Roelofs JJ, Claessen N, da Costa Martins P, Zwaginga JJ, et al (2005) Protection against renal ischemia reperfusion injury by CD44 disruption. J Am Soc Nephrol 16: 2034-2043.

24. Han DH, Song HK, Lee SY, Song JH, Piao SG, et al. (2010) Upregulation of hyaluronan and its binding receptors in an experimental model of chronic cyclosporine nephropathy. Nephrology (Carlton) 15: 216-224.

25. Li Y, Jiang D, Liang J, Meltzer EB, Gray A, et al. (2011) Severe lung fibrosis requires an invasive fibroblast phenotype regulated by hyaluronan and CD44 J Exp Med 208: 1459-1471.

26. Oliver JA, Barasch J, Yang J, Herzlinger D, Al-Awqati Q (2002) Metanephric mesenchyme contains embryonic renal stem cells. Am J Physiol Renal Physio 283: F799-809.

27. Oliver JA, Maarouf O, Cheema FH, Martens TP, Al-Awqati Q (2004) The renal papilla is a niche for adult kidney stem cells. J Clin Invest 114: 795-804.

28. Bao J, Tu Z, Sun H, Luo G, Yang L, et al. (2008) R2: identification of renal potential progenitor/stem cells that participate in the renal regeneration processes of kidney allograft fibrosis. Nephrology (Carlton) 13: 500-507.

29. Bussolati B, Bruno S, Grange C, Buttiglieri S, Deregibus MC, et al. (2005) Isolation of renal progenitor cells from adult human kidney. Am J Pathol 166 545-555.

30. Ye Y, Wang B, Jiang X, Hu W, Feng J, et al. (2011) Proliferative capacity of stem/progenitor-like cells in the kidney may associate with the outcome of patients with acute tubular necrosis. Hum Pathol 42: 1132-1141.

31. Oliver JA, Klinakis A, Cheema FH, Friedlander J, Sampogna RV, et al. (2009) Proliferation and migration of label-retaining cells of the kidney papilla. J Am Soc Nephrol 20: 2315-2327.

32. Smeets B, Angelotti ML, Rizzo P, Dijkman H, Lazzeri E, et al. (2009) Rena progenitor cells contribute to hyperplastic lesions of podocytopathies and crescentic glomerulonephritis. J Am Soc Nephrol 20: 2593-2603.

33. Witzgall R, Brown D, Schwarz C, Bonventre JV (1994) Localization of proliferating cell nuclear antigen, vimentin, c-Fos, and clusterin in the postischemic kidney. Evidence for a heterogenous genetic response among nephron segments, and a large pool of mitotically active and dedifferentiated cells. J Clin Invest 93: 2175-2188.

34. Toubeau G, Nonclercq D, Zanen J, Laurent G, Schaudies PR, et al. (1994) Renal tissue expression of EGF and EGF receptor after ischaemic tubular injury: an immunohistochemical study. Exp Nephrol 2: 229-239. 